\title{
Endometrial leucocytes: expression of steroid hormone receptors
}

\author{
J A Stewart, J N Bulmer, A P Murdoch
}

\begin{abstract}
Background-Stromal leucocyte populations in human endometrium comprise $T$ cells, macrophages, and phenotypically unusual endometrial granulated lymphocytes. Their proportions vary during the menstrual cycle and, in particular, endometrial granulated lymphocytes increase in number in the late secretory phase. The stimulus responsible for these cyclical changes is unknown but it is likely that the steroid hormones oestrogen and progesterone play a role.

Aims-To define further the expression of steroid hormone receptors by leucocytes in non-pregnant and pregnant human endometrium.

Methods-Frozen and paraffin wax embedded sections of endometrium from non-pregnant women and early pregnancy decidua were labelled using single and double immunohistochemical techniques with monoclonal antibodies directed against oestrogen and progesterone receptors and various leucocyte subpopulations.

Results-Despite the prominence of CD56 positive endometrial granulated lymphocytes in late secretory phase endometrium and early pregnancy decidua, double immunohistochemical labelling showed no evidence of expression of either progesterone or oestrogen receptors by these cells or other endometrial leucocyte populations.

Conclusions-Rather than acting directly, steroid hormones are likely to influence endometrial leucocyte populations indirectly via products of endometrial stromal or epithelial cells that express steroid hormone receptors.

(F Clin Pathol 1998;51:121-126)
\end{abstract}

Keywords: endometrium; steroid hormone receptors; granulated lymphocyte

Reproductive

Medicine, Royal

Victoria Infirmary,

Newcastle upon Tyne

NE1 4LP, UK

J A Stewart

A P Murdoch

Department of Pathology, Royal

Victoria Infirmary

J N Bulmer

Correspondence to:

Dr Stewart.

Accepted for publication 11 November 1997

The endometrium is a steroid sensitive organ that responds to oestrogen and progesterone in a cyclical fashion. The morphological cyclical response has been well documented. ${ }^{12}$ The stromal leucocyte populations in human endometrium also change during the menstrual cycle. ${ }^{3-5}$ Endometrial stromal leucocytes consist of $T$ cells that remain, numerically, relatively stable during the cycle, macrophages that increase in number as the cycle progresses towards menstruation, and phenotypically unusual endometrial granulated lymphocytes. Endometrial granulated lymphocytes increase in number dramatically in the late secretory phase of the menstrual cycle; if conception and implantation occur, endometrial granulated lymphocytes continue to increase in number and comprise around $70 \%$ of the stromal leucocytes in first trimester decidua. ${ }^{36}$

Immunohistochemical studies have demonstrated active proliferation of endometrial granulated lymphocytes in the late secretory phase of the menstrual cycle ${ }^{7}$ but the mechanisms that control the changes in endometrial leucocyte numbers are not known. In view of their cyclical nature and the influence on decidualisation, it appears likely that they respond to the sex steroid hormones that influence the menstrual cycle-oestrogen and progesterone. This could be a direct effect on the leucocytes, which must in consequence express the appropriate receptors, or an indirect effect mediated by products from other endometrial cells, which themselves express steroid receptors.

That leucocytes might be stimulated directly by sex steroids has been suggested by reports that peripheral blood CD8 positive $\mathrm{T}$ lymphocytes express progesterone receptors during pregnancy, ${ }^{8}$ although earlier binding studies excluded androgen, oestrogen, and progesterone receptors on peripheral blood lymphocytes, including those activated by phytohaemagglutinin. ${ }^{9}$ Progesterone is reported to inhibit lymphocyte proliferation but this action is not blocked by RU486, a progesterone (and glucocorticoid) antagonist, suggesting a mechanism not related to direct stimulation of progesterone receptors. ${ }^{10}{ }^{11} \mathrm{Im}$ munohistochemical studies of leucocytes in non-pregnant human endometrium have detected oestrogen receptor expression by $\mathrm{T}$ cells in aggregates in the basal endometrium ${ }^{12}$; however, King et al reported conflicting results, having shown no evidence of sex steroid hormone receptor expression by endometrial leucocytes. ${ }^{13}$ The latter study was confined to the general leucocyte population (CD45 positive), without examination of specific leucocyte subgroups.
This study was designed to examine more closely the possible expression of sex steroid receptors by endometrial leucocytes in pregnant and non-pregnant endometrium to clarify the mechanism of regulation of endometrial leucocyte numbers.

\section{Materials and methods}

FROZEN TISSUE

Fresh endometrial tissue was obtained from 15 hysterectomy specimens (five proliferative, five early secretory, and five late secretory) where 
the operation was performed for nonendometrial pathology such as fibroids, benign ovarian cysts, or persistent cervical intraepithelial neoplasia. All specimens had normal endometrial histology in keeping with the menstrual dates. Blocks (5-10 $\mathrm{mm}$ cubes) were snap frozen in liquid nitrogen cooled isopentane. Decidual tissue, identified macroscopically by its opaque grey-white appearance, was obtained from five early gestation suction terminations of pregnancy with fully informed consent. Decidual tissue was irrigated in normal saline to remove excess blood and snap frozen in a similar way in $5-10 \mathrm{~mm}$ cubes. All tissues were stored at $-70^{\circ} \mathrm{C}$.

Frozen sections of endometrium and decidua $(6 \mu \mathrm{m})$ were cut on to poly-L-lysine (Sigma Chemical Co, Poole, Dorset, UK) coated slides, air dried overnight at room temperature, fixed in acetone for 10 minutes at room temperature, and stored sealed at $-20^{\circ} \mathrm{C}$ until use. Haematoxylin and eosin staining was performed on all sections to check orientation and to ensure that an adequate amount of tissue with normal well preserved morphology was included.

\section{PARAFFIN WAX EMBEDDED TISSUE}

Sections $(3 \mu \mathrm{m})$ of late secretory phase endometrium $(\mathrm{n}=5)$ and normal first trimester decidua $(\mathrm{n}=5)$ from similar patient groups to those described above, were cut from archival paraffin wax blocks on to 3-aminopropyltriethoxysilane (APES) (Sigma) coated slides. Late secretory phase endometrium and decidua were used because maximal changes in endometrial leucocyte numbers occur in these samples. After the sections were deparaffinised and rehydrated, antigen unmasking was achieved by microwaving for $2 \times 5$ minutes in either $0.01 \mathrm{M}$ sodium citrate buffer, $\mathrm{pH} 6.0$ (BDH Chemical Company Ltd, Poole, Dorset, UK) ${ }^{14}{ }^{15}$ or, for ER-6F11 (see table 1), in $1 \mathrm{mM}$ EDTA buffer, pH 8.0 (BDH). After cooling, immunohistochemical staining was performed as outlined below.

MONOCLONAL ANTIBODIES

Antibody specificities, dilutions, and sources are given in table 1. ER-LH2 and PGR were used to identify the distribution of oestrogen and progesterone receptors by immunohistochemical labelling in frozen and paraffin wax sections. ER-LH2 was less satisfactory when used on paraffin wax embedded tissues and,

Table 1 Monoclonal antibodies

\begin{tabular}{|c|c|c|c|c|}
\hline \multirow[b]{2}{*}{ Antibody } & \multirow[b]{2}{*}{ Specificity } & \multirow[b]{2}{*}{ Source } & \multicolumn{2}{|c|}{ Dilution } \\
\hline & & & Frozen & Paraffin \\
\hline ER-LH2 & Oestrogen receptor & Novocastra & $1 / 30$ & $1 / 10$ \\
\hline ER-6F11 & Oestrogen receptor & Novocastra & & $1 / 10$ \\
\hline PR & Progesterone receptor & Novocastra & $1 / 100$ & $1 / 100$ \\
\hline CD3 & T lymphocytes & Dako & $1 / 200$ & \\
\hline CD3 & T lymphocytes & Novocastra & & $1 / 100$ \\
\hline CD14 & Macrophages & Dako & $1 / 20$ & \\
\hline $\mathrm{CD} 45$ & Leucocyte common antigen & Dako & $1 / 200$ & $1 / 200$ \\
\hline CD56 & Natural killer cells & Novocastra & $1 / 200$ & \\
\hline CD56 & Natural killer cells & Vector & & $1 / 100$ \\
\hline MT-1 & (CD43) Natural killer cells, T cells & Novocastra & & $1 / 40$ \\
\hline
\end{tabular}

Novocastra, Newcastle upon Tyne, UK; Dako, High Wycombe, Bucks, UK; Vector, Peterborough, UK therefore, it was substituted by ER-6F11, which gave good quality staining in paraffin wax embedded sections after high temperature antigen retrieval.

Leucocyte populations were identified by single and double immunohistochemical staining procedures using antibodies to CD45 (leucocyte common antigen), CD3 ( $T$ cells), and CD14 (macrophages). Endometrial granulated lymphocytes were identified using antibodies to CD56 and in paraffin wax embedded sections this was confirmed using the MT-1 antibody. ${ }^{16}$

IMMUNOHISTOCHEMICAL LABELLING PROCEDURES Single labelling

Single immunohistochemical labelling was performed using the Vectastain Elite ABC kit (Vector Laboratories, Peterborough, UK) and secondary and tertiary reagents were prepared according to the kit instructions. ${ }^{17}$ After initial rehydration for 10 minutes in $0.05 \mathrm{M}$ Tris buffered $0.15 \mathrm{M}$ saline, pH 7.6 (TBS; Sigma), sections were overlain for 30 minutes with serum from the same species in which the secondary antibody had been raised to block nonspecific binding. The slides were then incubated with primary monoclonal antibody at the appropriate dilution in TBS for 60 minutes. After washing in TBS, biotinylated secondary antibody was applied for 30 minutes, followed by further washing and incubation with $\mathrm{ABC}$ reagent for 30 minutes. A third wash was followed by incubation with the peroxidase substrate, amino-ethyl carbazole (AEC; Vector), to give a red reaction product. This reaction was monitored microscopically and stopped after $\sim 15$ minutes with excess water. The sections were counterstained lightly with Mayer's haematoxylin.

\section{Double labelling}

Double immunohistochemical labelling was performed to detect any coexpression of steroid receptors by endometrial leucocyte populations. Sections were labelled initially for leucocyte antigens with the ABC method described above. After development of the red reaction product, sections were washed in TBS for 10 minutes, overlain with blocking serum for a further 30 minutes, and incubated with the second primary antibody directed against either the oestrogen receptor or the progesterone receptor for 60 minutes. After further washing in TBS, sections were incubated for 30 minutes with biotinylated secondary antibody washed in TBS and incubated with ABC alkaline phosphatase (Vectastain alkaline phosphatase kit) for 30 minutes. The reaction was developed using the alkaline phosphatase substrate kit III (Vecta Blue; Vector); sections were incubated at room temperature until the appropriate blue colour developed, usually $\sim 10$ minutes. The reaction was stopped by excess water. Double labelled slides were not counterstained. Table 2 shows the double labelling combinations prepared.

All slides were mounted initially in Supermount (BioGenex, San Ramon, USA) and, 
Table 2 Double labelling combinations

\begin{tabular}{|c|c|c|c|c|c|}
\hline \multirow[b]{2}{*}{ Antibody } & \multicolumn{2}{|c|}{ Frozen sections } & \multicolumn{3}{|c|}{ Paraffin sections } \\
\hline & $E R-L H 2$ & $P R$ & $E R-L H 2$ & $E R-6 F 11$ & $P R$ \\
\hline CD45 & Yes & Yes & Yes & Yes & Yes \\
\hline CD3 & Yes & Yes & No & Yes & Yes \\
\hline CD56 & Yes & Yes & No & Yes & Yes \\
\hline CD14 & Yes & Yes & No & No & No \\
\hline MT-1 & No & No & Yes & Yes & Yes \\
\hline
\end{tabular}

$\mathrm{ER}$, oestrogen receptor; PR, progesterone receptor.

after overnight drying, with DPX mountant $(\mathrm{BDH})$ and coverslips.

\section{CONTROLS}

Frozen or fixed sections of tonsil were included in all runs as positive controls for leucocyte markers. The distribution of oestrogen and progesterone receptors in human endometrium and myometrium is well documented and stromal, glandular, and myometrial cells therefore acted as inbuilt positive controls. Negative controls were performed for each tissue by replacement of the primary antibody with serum. For each double labelled section the primary antibody was omitted from each stage of the technique in turn. The different antibody/enzyme/substrate combinations were also reversed in the double labelled runs to confirm consistency of the reaction patterns with the different enzyme labels. The single labelled and double labelled slides were compared to confirm consistent distribution of labelling in each tissue and to check that no spurious double labelling had occurred.

ANALYSIS

All sections were analysed qualitatively for double and single labelling.

\section{Results}

Large numbers of CD45 positive cells were identified throughout the endometrium (fig 1A) and decidua, with aggregates adjacent to glands and vessels (fig 1B). CD3 positive cells were present in all the frozen tissues, with aggregates in the stratum basalis, particularly adjacent to glands (fig 1C). There was a pronounced increase in CD56 positive cells in secretory phase and decidual tissues compared with proliferative endometrium, findings complemented by the increased number of MT-1 positive cells in formalin fixed, paraffin wax embedded tissues (fig 1D). MT-1 also reacted with $\mathrm{T}$ cells in the endometrium. Only small numbers of CD14 positive cells were identified in all frozen tissues studied.

In frozen and fixed tissues, the oestrogen receptor was expressed in both the epithelium and stroma in proliferative and secretory phase endometrium (fig 1A-D), although glandular staining was reduced in the mid and late luteal phases. Oestrogen receptor staining was present throughout the decidual stroma (fig $1 \mathrm{E}$ and $1 \mathrm{~F}$ ). Only oestrogen receptors were expressed by epithelial cells of decidualised endometrium.

The progesterone receptor was expressed to a variable degree in some glands in proliferative endometrium but, in general, glands were negative in the luteal phase (fig $2 \mathrm{~A}$ and $2 \mathrm{~B}$ ). Progesterone receptors were expressed throughout the stroma in both phases of the cycle (fig 2A-D) in non-pregnant endometrium and throughout the decidual stroma (fig 2E). The results of single labelling of both frozen and paraffin wax embedded sections were in keeping with previous observations. $^{3} 1819$

There was no evidence of double labelling of either the oestrogen receptor or the progesterone receptor in any of the leucocyte populations in any of the sections examined (fig 1A-E). In particular, the $\mathrm{T}$ cell aggregates in the stratum basalis (CD3 positive and MT-1 positive) did not show steroid receptor binding (fig 1C). CD56-positive cells (and MT-1 positive cells in paraffin wax sections) did not express oestrogen or progesterone receptors at any stage of the cycle (figs $1 \mathrm{C}, 2 \mathrm{~B}, 2 \mathrm{C}, 2 \mathrm{~F}$, and $2 \mathrm{G}$ ).

\section{Discussion}

The cyclical effects of the sex steroids oestrogen and progesterone on the endometrium are integral to the menstrual cycle and the histological changes have been well documented. ${ }^{20}{ }^{21}$ Immunohistochemical studies have characterised the glandular and stromal distribution of sex steroid receptors during the menstrual cycle. ${ }^{1822}{ }^{23}$ Although the cyclical changes in endometrial leucocyte populations are dramatic and have been well documented, the mechanisms controlling these changes have not been defined.

In general, studies of endometrial steroid receptor expression do not mention specifically the leucocytes that comprise a large proportion of stromal cells, particularly in the late secretory phase of the cycle. Tabibzadeh and Satyaswaroop $^{12}$ reported that a small proportion $(1-7 \%)$ of $\mathrm{T}$ lymphocytes in basal endometrial aggregates expressed oestrogen receptors. This contrasts with the results of the present study, in which sex steroid receptors were not detected on any group of endometrial leucocytes, and which also showed absence of oestrogen receptors on T lymphocytes in lymphoid aggregates in the basal layer of the endometrium. The discrepancies in results between these two studies could be due to differences in the immunohistochemical techniques used. Tabibzadeh and Satyaswaroop ${ }^{12}$ used peroxidase labelled secondary antibodies for both primary antibodies in double immunohistochemical labelling. In the present study two different enzyme systems were used. Furthermore, in the earlier study, endogenous peroxidase activity was revealed by 4-chloro-1naphthol, resulting in a blue reaction product, ${ }^{12}$ and it is not clear how this was differentiated from specific staining with $\mathrm{CN}-\mathrm{H}_{2} \mathrm{O}_{2}$, which also produced a blue reaction product. The red and blue reaction products used for double immunostaining techniques in the present study were easier to distinguish between than the blue and brown/black reaction products of the previous study. Differences may also result from the use of different monoclonal antibodies with different specificities. The present study used two anti-oestrogen receptor 
antibodies (ER-LH2 and ER-6F11) and two antibodies to detect endometrial granulated lymphocytes (CD56 and MT-1). Consistent and compatible results were obtained throughout the study. The use of both paraffin wax embedded and frozen sections indicates that
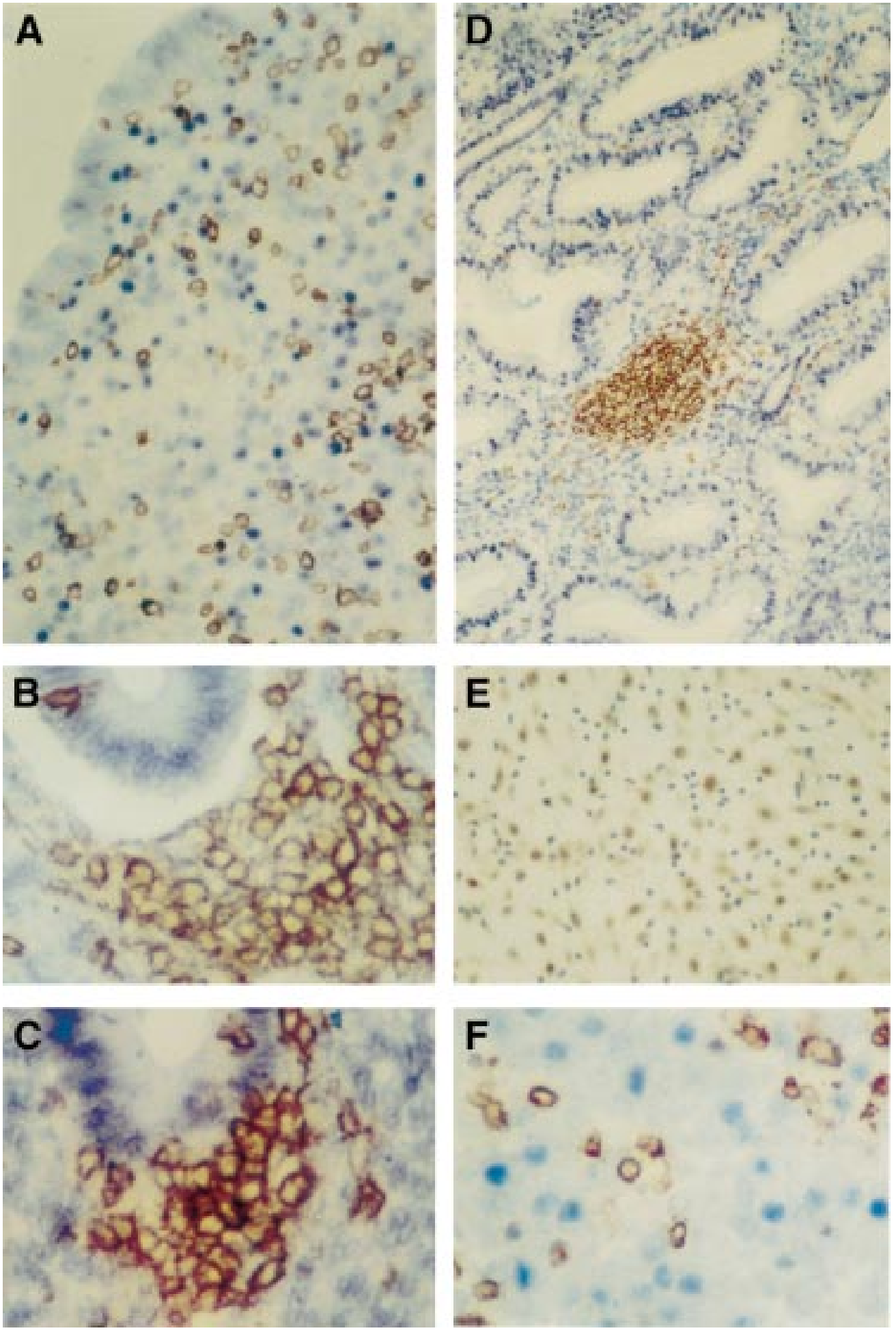

Figure 1 Double immunohistochemical labelling: paraffin wax section of secretory endometrium, antibodie ER6F11/CD45 (A); paraffin wax section of secretory endometrium, antibodies ER6F11/CD45 (B); paraffin wax section of secretory endometrium, antibodies ER6F11/MT-1 (C); paraffin wax section of secretory endometrium, antibodies ER6F11/MT-1 (D); paraffin wax section of decidua, antibodies ER6F11/CD45 (F). In all cases leucocyte cell membranes are labelled red and the oestrogen receptor is demonstrated by blue nuclear reactivity. Single immunohistochemical labelling: paraffin wax section of decidua showing brown oestrogen receptor nuclear positivity in non-leucocyte stromal cells, antibody ER6F11 (E).

the tissue preparation alone is not responsible or the negative findings.

Recently, King et al reported similar results. ${ }^{13}$ Fixed tissue was examined and double immunostaining techniques similar to those used here were used, although the study was
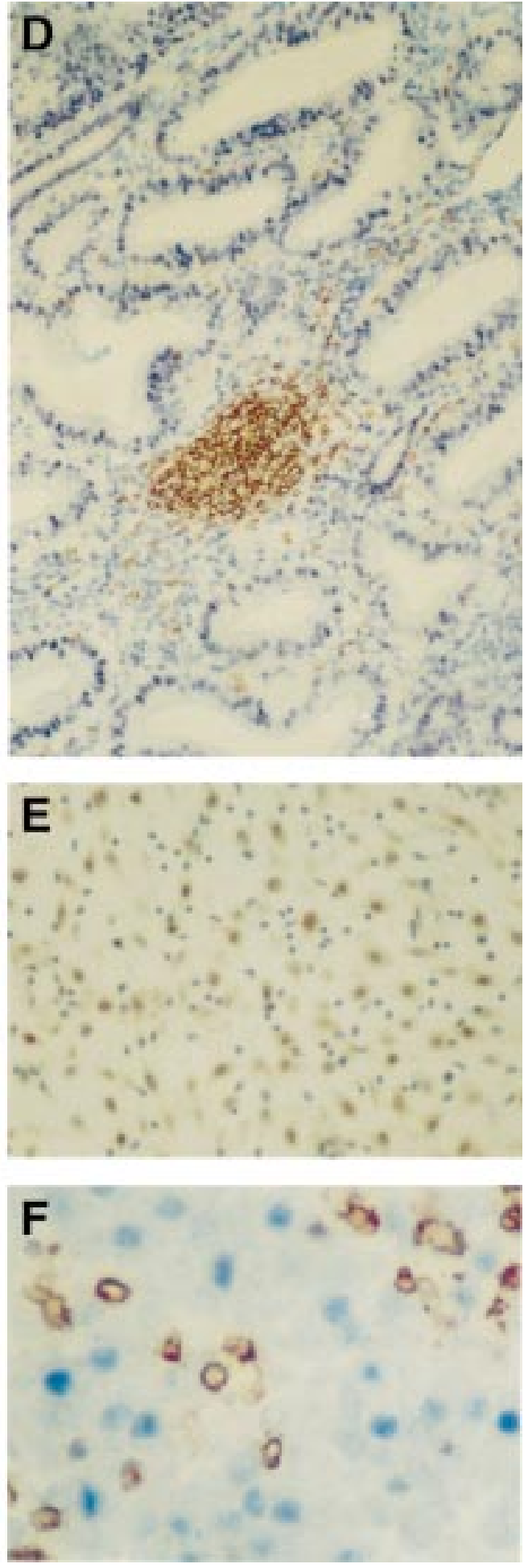
confined to labelling for oestrogen and progesterone receptors and CD45 (leucocyte common antigen), because of the limitations of anti-CD56 in fixed sections. Furthermore, the authors failed to demonstrate specific oestrogen receptor labelling in decidual tissue. This may be owing to the relative unsuitability of ER-LH2 for paraffin wax embedded sections.
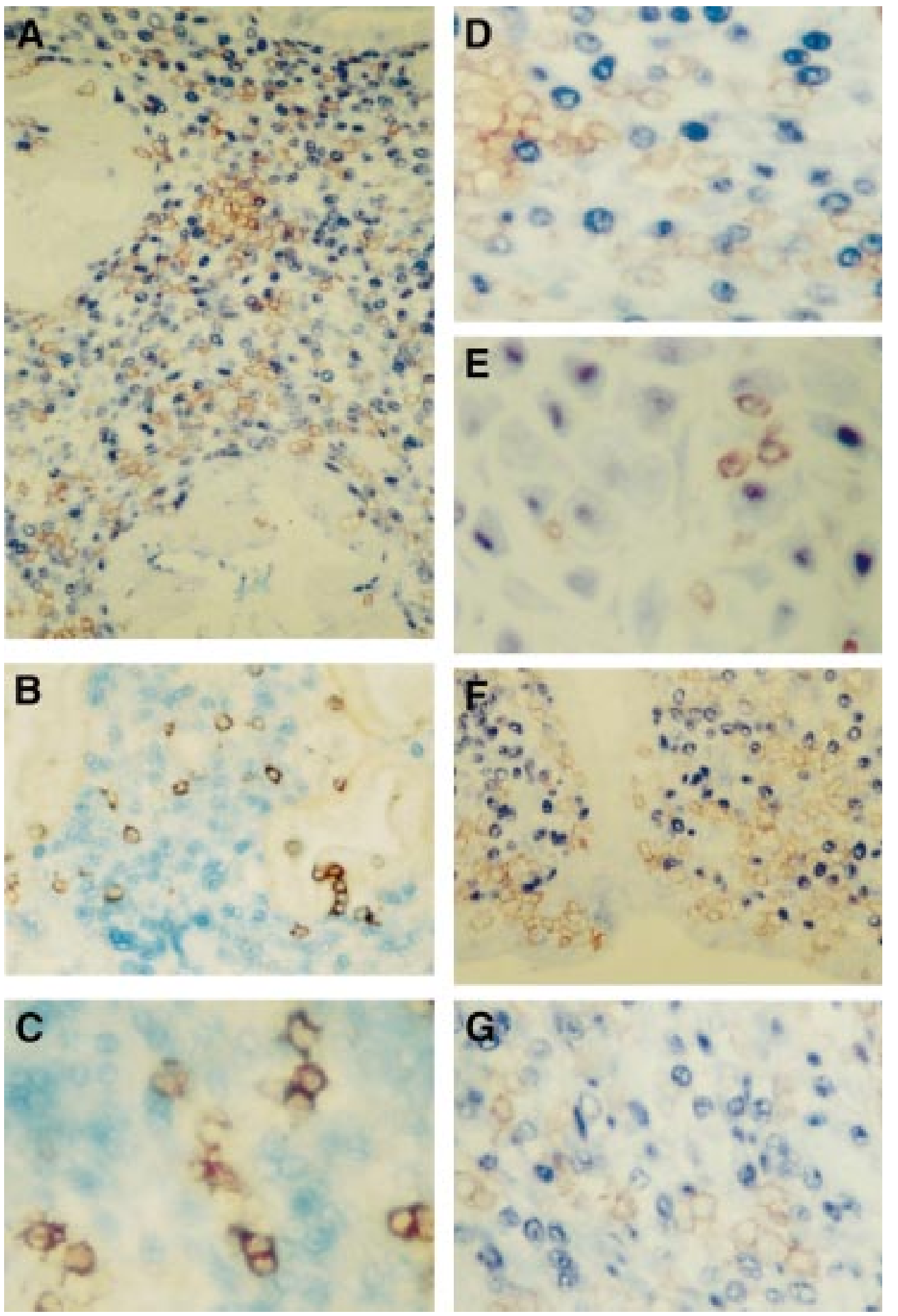

Figure 2 Double immunohistochemical labelling: paraffin wax section of secretory endometrium, antibodies PR/CD45 $(A)$; frozen section of secretory endometrium, antibodies $P R / C D 56(B)$; frozen section of secretory endometrium, antibodies $P R / C D 56$ (C); paraffin wax section of secretory endometrium, antibodies $P R / C D 45$ (D); paraffin wax section of decidua, antibodies $P R / C D 45$ (E); paraffin wax section of secretory endometrium, antibodies PR/MT-1 (F); paraffin wax section of secretory endometrium, antibodies PR/MT-1 $(G)$. In all cases leucocyte cell membranes are labelled red and the progesterone receptor is demonstrated by blue nuclear reactivity.
In the current study, it was found that a newer antibody, ER-6F11, gave greatly improved labelling in paraffin wax embedded endometrial sections and also confirmed oestrogen receptor expression in decidual tissue, as has been reported elsewhere. ${ }^{19}$

Although the present study excludes the possibility of a direct effect on endometrial
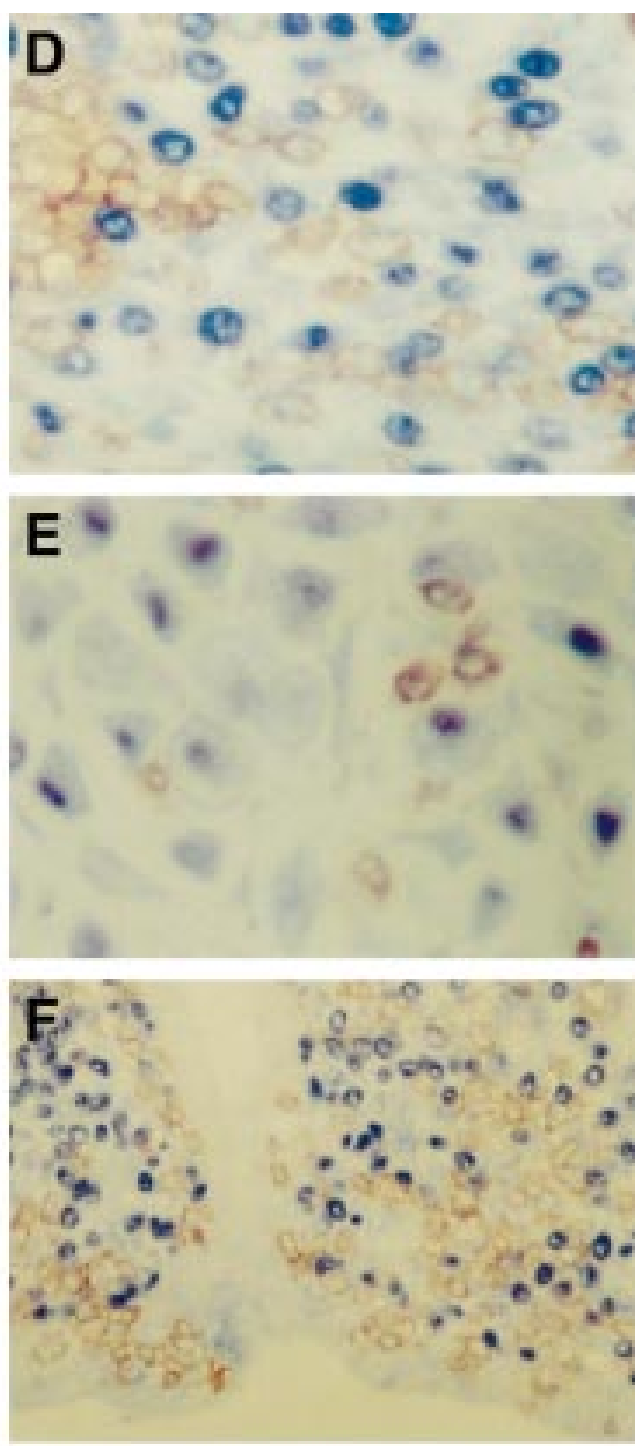

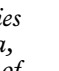


leucocytes by progesterone and oestrogen, it does not exclude an indirect effect via stromal or epithelial mediators such as cytokines. Endometrium derived cytokines include interferon $\gamma(\mathrm{IFN} \gamma)$, interleukin 1 (IL-1), tumour growth factor $\alpha(\mathrm{TGF} \alpha)$, TGF $\beta$, granulocytemacrophage colony stimulating factor (GMCSF), CSF-1, IL-6, and tumour necrosis factor $\alpha(\mathrm{TNF} \alpha){ }^{24}{ }^{25}$ Leucocytes are known to respond to cytokines in vitro and it is possible, therefore, that they act as second messengers to sex steroids in the control of proliferation and the function of endometrial leucocytes. Laird $e t$ al reported modulation of IL- 6 production by endometrial epithelial and stromal cell cultures on addition of oestradiol, ${ }^{26}$ either alone or in combination with progesterone, later showing that this is cycle stage dependent. ${ }^{24}$ IL- 6 can also be modulated by other peptides produced by the endometrium, namely IL- 1 and placental protein 14 (PP14), which are themselves known to be steroid dependent. ${ }^{27}$ Similarly, production of IL-8 (neutrophil activating factor) by endometrial cells in culture has been reported to be reduced by the addition of progesterone or dexamethasone. These are examples of a series of complex interactions being untangled currently, which may represent the fine tuning of any endometrial immune response to temporal changes in steroid stimulation throughout the menstrual cycle.

Ultimately, the role of the endometrium is to provide a site for both embryo implantation and its subsequent development during pregnancy. Sex steroids, and consequently their effectors, must therefore control the environment in which this happens. That endometrial leucocytes play a role in fertility is suggested by immunohistochemical studies documenting a reduction in $\mathrm{CD} 8+\mathrm{T}$ cells and an increase in $\mathrm{CD} 4+\mathrm{T}$ cells throughout the luteal phase in endometrium from women with unexplained infertility. ${ }^{28}$ Further studies of the regulation of endometrial immune cell populations should examine regulation of both cell numbers and function by soluble factors produced by endothelial stromal and epithelial cells in response to altered steroid hormone levels.

The authors acknowledge the able laboratory assistance of Mrs $S$ Turner. This work was supported by grants from the Wellcome Trust and Newcastle University and Hospitals Special Trustees.

1 Noyes RW, Hertig AI, Rock J. Dating the endometrial biopsy. Fertil Steril 1950;1:3-25.

$2 \mathrm{Li}$ T-C, Rogers AW, Dockery P, et al. A new method of histologic dating of human endometrium in the luteal phase. Fertil Steril 1988;50:52-60.

3 Bulmer JN, Morrison L, Longfellow M, et al. Granulated lymphocytes in human endometrium: histochemical and immunohistochemical studies. Hum Reprod 1991;6:791-8.

4 King A, Wellings V, Gardner L, et al. Immunocytochemical characterisation of the unusual large granular lymphocytes in human endometrium throughout the menstrual cycle. Hum Immunol 1989;24:195-205.

5 Starkey PM, Clover LM, Rees MCP. Variation during the menstrual cycle of immune cell populations in human endometrium. Eur $\mathcal{F}$ Obstet Gynecol Reprod Biol 1991;39: 203-7.

6 Klentzeris LD, Bulmer JN, Warren A, et al. Endometrial lymphoid tissue in the timed endometrial biopsy: morphometric and immunohistochemical aspects. Am 7 Obstet Gynecol 1992;167:667-74.

7 Pace D, Morrison L, Bulmer JN. Proliferative activity in endometrial stromal granulocytes throughout menstrual cycle and early pregnancy. $\mathcal{F}$ Clin Pathol 1989;42:35-9.

8 Szekeres-Bartho J, Szekeres G, Debre P, et al. Reactivity of ymphocytes to a progesterone receptor-specific monoclonal antibody. Cell Immunol 1990;125:273-83.

9 Neifeld JP, Lippman ME, Tormey DC. Steroid hormone receptors in normal human lymphocytes. 7 Biol Chem 1977;252:2972-7.

10 Monterroso VH, Hansen PJ. Regulation of bovine and ovine lymphocyte proliferation by progesterone: modulation by steroid receptor antagonists and physiological status. Acta Endocrinol 1993;129:532-5.

11 van Voorhis BJ, Anderson DJ, Hill JA. The effects of RU486 on immune function and steroid-induced immunosuppres ion in vitro. F Clin Endocrinol Metab 1989;69:1195-9.

12 Tabibzadeh SS, Satyaswaroop PG. Sex steroid receptors in ymphoid cells of human endometrium. Am f Clin Pathol 1989;91:656-63.

13 King A, Gardner L, Loke YW. Evaluation of oestrogen and progesterone receptor expression in uterine mucosal lymphocytes. Hum Reprod 1996;11:1079-82.

14 Norton AJ. Microwave oven heating for antigen unmasking in routinely processed tissue sections. F Pathol 1993;171: $79-80$.

15 Cattoretti G, Pileri S, Parravicini C, et al. Antigen unmasking on formalin-fixed, paraffin-embedded tissue sections. $\mathcal{F}$ Pathol 1993;171:83-98.

16 Bulmer JN, Hollings D, Ritson A. Immunocytochemical evidence that endometrial stromal granulocytes are granulated lymphocytes. F Pathol 1987;153:281-8.

17 Hsu S-M, Raine L, Fanger H. Use of avidin-biotinperoxidase complex (ABC) in immunoperoxidase techniques: a comparison between $\mathrm{ABC}$ and unlabelled antibody (PAP) procedures. F Histochem Cytochem 1981;29: 577-80.

18 Coppens MT, Dhont MA, De Boever JG, et al. The distribution of oestrogen and progesterone receptors in the human endometrial basal and functional layer during the normal menstrual cycle. Histochemistry 1993;99:121-6.

19 Wu W-X, Brooks J, Millar MR, et al. Immunolocalization of oestrogen and progesterone receptors in the human decidua in relation to prolactin production. Hum Reprod 1993;8:1129-35.

20 Good RG, Moyer DL. Estrogen-progesterone relationships in the development of secretory endometrium. Fertil Steril 1968;19:37-49.

21 March CM. The endometrium in the menstrual cycle. In: Mishell DR, Davajan V, Lobo RA, eds. Infertility, contraception and reproductive endocrinology, 3rd ed. Boston: Blackwell Scientific, 1991:125-39.

22 Amso NN, Crow J, Shaw RW. Comparative immunohistochemical study of oestrogen and progesterone receptors in the fallopian tube and uterus at different stages of the menstrual cycle and the menopause. Hum Reprod 1994;9:102737.

23 Press MJ, Udove JA, Greene GL. Progesterone receptor distribution in the human endometrium. Am $\mathcal{f}$ Pathol 1988;131:112-24.

24 Laird SM, Tuckerman E, Li T-C, et al. Stimulation of human endometrial epithelial cell interleukin 6 production by interleukin 1 and placental protein. Hum Reprod 1994;9: by interleukin 43 .

25 Tabibzadeh, S. Cytokines and the hypothalamic-pituitaryovarian-endometrial axis. Hum Reprod 1994;9:947-67.

26 Laird SM, Li T-C, Bolton AE. The production of placental protein 14 and interleukin 6 by human endometrial cells in culture. Hum Reprod 1993;8:793-8.

27 Kelly RW, Illingworth P, Baldie G, et al. Progesterone control of interleukin-8 production in endometrium and chorio-decidual cells underlines the role of the neutrophil in menstruation and parturition. Hum Reprod 1994;9:2538.

28 Klentzeris LD, Bulmer JN, Warren MA, et al. Lymphoid tissue in the endometrium of women with unexplained infertility: morphometric and immunohistochemical aspects. Hum Reprod 1994;9:646-52. 